\title{
A FORMAÇÃO DIDÁTICA DO DOCENTE UNIVERSITÁRIO
}

\author{
THE EDUCATIONAL TRAINING OF UNIVERSITY TEACHERS
}

\section{LA FORMACIÓN DIDÁCTICA DEL DOCENTE UNIVERSITARIO}

\section{Monica de Souza Massa ${ }^{1}$ \\ Cristina Maria D’Avila Teixeira ${ }^{2}$}

RESUMO: Este artigo pretende discutir os aspectos conjunturais subjacentes à formação do professor universitário, a partir da análise do Instrumento de Avaliação de Cursos de Graduação Presencial e a Distância, documento disponibilizado pelo Instituto Nacional de Estudos e Pesquisas Educacionais Anísio Teixeira (INEP). Resulta de recorte em pesquisa desenvolvida nos cursos de Análise de Sistemas e Sistemas de Informação da Universidade do Estado da Bahia (2013/2014). O documento, que esclarece os critérios de avaliação relativos aos cursos de graduação em organização didático-pedagógica, corpo docente e infraestrutura, foi analisado através da técnica de análise temática. Como resultado do estudo realizado, identifica-se a pouca importância conferida à prática docente no ensino superior e os problemas dela decorrentes, relacionados à identidade profissional e à sua formação pedagógica.

PALAVRAS-CHAVE: Educação superior. Docente universitário. Formação de professores

ABSTRACT: This article aims to discuss the conjunctural aspects underlying the undergraduate teacher formation, based on the analysis of the Evaluation Instrument for Presencial and Distance Undergraduated Courses, document provided by National Institute of Educational Studies and Research Anísio Teixeira (INEP). It results from a research study developed in the System Analysis and Information Systems courses at UNEB State University of Bahia (2013/2014). The document, which defines the evaluation criteria related to undergraduate courses in didactic-pedagogical organization, teachers and infrastructure, was analyzed through the thematic analysis technique. As a result of the study, the low importance given to teaching practice in higher education is identified, and the problems arising from it, related to professional identity and pedagogical training.

KEYWORDS: Higher education. Undergraduate teacher. Teacher formation.

RESUMEN: Este artículo pretende discutir los aspectos coyunturales subyacentes a la formación del profesor universitario, a partir del análisis del instrumento de Evaluación de Cursos de Graduación Presencial y a Distancia, documento disponibilizado por el Instituto Nacional de Estudios y Pesquisas Educacionais Anísio Teixeira (INEP). Se deriva de recorte en investigación desarrollada en los cursos de Análisis de Sistemas y Sistemas de información de la Universidad del Estado de Bahia (2013/2014). El documento, que aclara los criterios de evaluación relativos a los cursos de graduación en organización didáctico-pedagógica, cuerpo docente e infraestructura, fue analizado a través de la técnica de análisis temática. Como resultado del estudio realizado se identifica la poca importancia conferida a la práctica docente en la educación superior y a los problemas de ella derivados, relacionados con la identidad profesional y con la formación pedagógica.

PALABRAS ClAVE: Educación superior. Docente universitario. Formación de profesores.

\footnotetext{
${ }^{1}$ Submetido em: 01/03/2018 - Aceito em: 02/05/2018 - Publicado em: 18/10/2018
}

\begin{tabular}{l|l|l|l|l|l|l} 
(C) Rev. Educ. Perspec. & Viçosa, $M G$ & v.9 & n.2 & p.230-240 & maio/ago. 2018 & eISSN 2178-8359 \\
\hline
\end{tabular}




\section{INTRODUÇÃO}

Uma profissão muito antiga, mas ainda pouco estudada. Docência, o que vem a ser? Docência deriva do latim - doccere - que significa "ensinar, instruir, mostrar, indicar, dar a entender" (VEIGA, 2009, p. 13). Segundo a autora, esse é um termo novo na língua portuguesa (datado de 1916), o que significa dizer que sua apropriação nos espaços acadêmicos é, paradoxalmente, algo recente.

A docência tem por objetivo a aprendizagem por parte do estudante. São complementares, portanto, a ação de ensinar (doccere) e a ação de aprender (discere). As atividades docentes, que caracterizam o trabalho dos professores, não estão restritas à sala de aula. São vários os autores que apontam as atividades docentes englobando o ensino, a pesquisa, a extensão e a gestão acadêmica (ZABALZA, 2004; VEIGA, 2009; SOARES; CUNHA, 2010; GARCIA, 2013).

Considerando o exposto acima, a formação dos professores é uma construção complexa, que implica na formação do futuro profissional para o exercício da docência. Assim, extrapola o simples "aprender a ensinar determinados conteúdos", envolvendo a problematização e a construção de competências relacionadas ao ensino, aprendizagem, avaliação e gestão educacional, entre outros. É um processo contínuo e progressivo, que deve ser compatível com o contexto (social, político e econômico), deve preparar o indivíduo para a mudança e deve estar articulada com a formação pessoal do indivíduo e com as experiências por ele vivenciadas (VEIGA, 2009). Portanto, além da formação técnica, envolve um conjunto de atitudes que incluem o pensamento crítico, as relações interpessoais, a criatividade, a autonomia, a cooperação e a solidariedade.

Em relação ao segmento do Ensino Superior, destacamos o crescimento expressivo da categoria e a lacuna de produção científica na área, o que justifica o nosso objeto de investigação. De acordo com o Censo da Educação Superior, no período de 10 anos - de 2006 a 2016 - houve um crescimento de cerca de 30\% de docentes universitários no País (INEP, 2016). No entanto, conforme aponta Morosini (2000), ainda existe uma lacuna de produção científica sobre o tema, faltando estudos que possibilitem uma compreensão sobre quem é esse professor universitário, suas origens, seu processo formativo e sua disponibilidade para acompanhar as mudanças sociais da contemporaneidade.

O objetivo deste artigo, enquanto recorte da investigação de doutorado da primeira autora, é apresentar uma análise sobre o docente do ensino superior em relação à sua formação didática e pedagógica. Os estudos que apresentamos neste documento são resultantes de uma extensa revisão bibliográfica, utilizada como apoio para a condução da investigação, tanto na

\begin{tabular}{l|c|c|c|c|c|c} 
(C) Rev. Educ. Perspec. & Viçosa, $M G$ & v.9 & n.2 & p.230-240 & maio/ago. 2018 & eISSN 2178-8359 \\
\hline
\end{tabular}


definição dos eixos norteadores quanto na análise dos dados coletados junto ao grupo alvo da pesquisa, buscando responder a uma das questões da pesquisa de doutoramento: "Como ensinam os docentes do ensino superior?"

Esse recorte, portanto, trata-se de uma pesquisa documental, que parte de uma revisão de literatura sobre o tema (tomando autores reconhecidos na área) e da análise dos critérios de avaliação acerca do corpo docente dos cursos de graduação presentes no instrumento de avaliação do INEP, buscando evidências acerca da percepção dos órgãos regulamentadores sobre as necessidades de formação didática e pedagógica do docente universitário.

\section{A FORMAÇÃo PEDAGÓGICA DO PROFESSOR UNIVERSITÁRIO}

Diversos autores, como Cunha (1998), Morosini (2000), D’Ávila (2008), Pimenta e Anastasiou (2010), entre outros, discutem a preparação dos docentes do ensino superior para o exercício da profissão e a carência da sua formação pedagógica.

Inicialmente temos os cursos de formação inicial como uma possibilidade de formação docente. Embora esses cursos tenham por objetivo a formação de professores para a educação básica, o indivíduo nessa formação inicial aprende a "ser professor". Caso ele ingresse em um curso de pós-graduação para complementar seus estudos, ele tem um maior preparo para a docência universitária do que um bacharel com a mesma formação.

Outra opção para a formação docente são os cursos de especialização de Metodologia do Ensino Superior e os cursos desenvolvidos pelas próprias Instituições de Ensino Superior (IES) para os seus professores. Em relação ao primeiro, Pimenta (2012) afirma que os currículos e as atividades propostas por estes cursos estão distantes da realidade da prática social educativa que o docente enfrentará no exercício da sua profissão. Em relação ao segundo, como critica Garcia (2013), a maioria dos cursos dessa natureza são curtos, focados em questões administrativas e pouco atentos às práticas pedagógicas. Tais cursos estão, portanto, longe de atender a complexidade da atividade docente.

De acordo com Pimenta e Anastasiou (2010) e Garcia (2013), o caminho frequentemente seguido por um número expressivo de docentes do ensino superior para a sua formação é a pós-graduação stricto sensu, o que transfere a responsabilidade da formação pedagógica do professor para os cursos de mestrado e doutorado. Tais cursos, na realidade, formam pesquisadores e não docentes, e a preocupação com a formação docente fica restrita à uma disciplina de Metodologia do Ensino Superior ou ao Estágio Supervisionado de Docência. 
Acreditamos que a busca do docente universitário por esse caminho formativo reside, em grande parte, nas demandas da legislação brasileira pela titulação e, correspondentemente, na ausência dessa demanda em relação à formação pedagógica. A Lei de Diretrizes e Bases da Educação Nacional - LDBEN 9394/96 (BRASIL, 1996), se pronuncia vagamente sobre a formação didática do professor universitário, reduzindo a sua competência ao domínio da área de conhecimento na qual ele atua e cobrando das IES apenas a titulação e o regime de trabalho do seu corpo docente. Ao omitir a necessidade da formação didática do professor universitário, o documento faculta este quesito junto às IES e, assim, o que seleciona este professor no ensino superior é a sua competência na área de conhecimento específico, obtida através dos cursos de graduação, mestrado e doutorado realizados no âmbito da sua formação técnica. No entanto, ao longo do exercício da docência, é exigido deste profissional um conjunto de competências, como por exemplo, a capacidade de comunicação com os discentes e a competência de utilizar variadas formas de ensino, embora ele não tenha em sua formação a oportunidade de desenvolvimento desses aspectos fundamentais para o exercício de sua profissão.

Buscando encontrar outros indicadores na legislação brasileira sobre a formação do docente no ensino superior, analisamos a última versão do Instrumento de Avaliação de Cursos de Graduação Presencial e a Distância (INEP, 2017), disponibilizado em outubro de 2017 pelo Instituto Nacional de Estudos e Pesquisas Educacionais Anísio Teixeira (INEP). Este documento apresenta três dimensões: a organização didático-pedagógica do curso, o seu corpo docente e tutorial e a infraestrutura disponível. Consideramos para a nossa análise a segunda dimensão, que apresenta dezesseis indicadores de qualidade do grupo de professores de um curso de graduação.

O primeiro item aborda o Núcleo Docente Estruturante (NDE) do curso, avaliando quantitativamente o regime de trabalho e a titulação de seus componentes. Além disso, analisa qualitativamente a atuação deste núcleo na consolidação do projeto pedagógico do curso. Neste quesito não é avaliada a formação pedagógica dos membros do NDE - o que seria pertinente considerando que os docentes que compõem este núcleo têm por função atuar no processo de concepção, consolidação, acompanhamento e avaliação do Projeto Pedagógico do Curso, que demandam diversos conhecimentos da área da pedagogia.

Os itens 03 e 04 versam sobre o coordenador do curso. Avaliam de forma qualitativa a atuação do coordenador como gestor do curso, a sua relação com os docentes e discentes e a sua representatividade nos colegiados superiores. Além disso, avaliam quantitativamente o regime de trabalho deste profissional. Observamos que nenhum dos itens acima mencionados avalia a formação pedagógica do coordenador do curso, nem tampouco a sua titulação. Cabe problematizarmos sobre o que significa ser gestor de um curso de graduação. Acreditamos que, no escopo das tarefas gerenciais e acadêmicas do coordenador do curso, devam ser

\begin{tabular}{l|c|c|c|c|c|c} 
() Rev. Educ. Perspec. & Viçosa, $M G$ & v.9 & n.2 & p.230-240 & maio/ago. 2018 & eISSN 2178-8359 \\
\hline
\end{tabular}


requeridos conhecimentos relacionados à gestão educacional, currículo e avaliação, entre outros. Nenhum destes quesitos é contemplado na avaliação do coordenador do curso.

Situação similar ocorre na análise do corpo docente do curso, nos itens de 05 a 10 do mesmo documento. São avaliados: titulação do corpo docente, regime de trabalho do corpo docente, experiência profissional do docente (no mundo do trabalho), experiência no exercício da docência na educação básica (para cursos de licenciatura) e experiência no exercício da docência superior e da docência na educação a distância (para os cursos ofertados nesta modalidade). Não encontramos nenhuma evidência na lista de indicadores de análise do corpo docente referente à formação pedagógica inicial e continuada nem tampouco à adoção de práticas inovadoras de ensino e aprendizagem. Observamos que, nos últimos dois itens, existe uma preocupação com a experiência no exercício da docência. $\mathrm{O}$ trecho a seguir aponta a condição de nota máxima para estes quesitos:

\begin{abstract}
O corpo docente possui experiência na docência superior para promover ações que permitem identificar as dificuldades dos discentes, expor o conteúdo em linguagem aderente às características da turma, apresentar exemplos contextualizados com os conteúdos dos componentes curriculares, e elaborar atividades específicas para a promoção da aprendizagem de discentes com dificuldades e avaliações diagnósticas, formativas e somativas, utilizando os resultados para redefinição de sua prática docente no período, exerce liderança e é reconhecido pela sua produção (INEP, 2017, p. 26)
\end{abstract}

A análise do texto nos permite inferir que a preocupação apontada anteriormente reside na ideia de que a experiência no exercício da docência seria o necessário para conferir ao professor do ensino superior condições para uma mediação didática de excelência.

Por fim, a percepção da falta de indicadores específicos que avaliem a formação pedagógica do professor universitário no documento de Avaliação de Cursos do INEP, bem como a falta de elementos que explicitem essa necessidade no texto da LDBEN, parecem confirmar a falta de preocupação com a formação pedagógica no ensino superior. Com efeito, Fernandes (1998) questiona porque é exigida uma formação pedagógica do professor do ensino fundamental e médio, ao passo que ao professor universitário é facultada a ausência dessa formação e Pimenta e Anastasiou (2010, p. 36) também observam que “[...] há um certo consenso de que a docência no ensino superior não requer formação no campo de ensinar".

De forma análoga, a transferência da responsabilidade da formação pedagógica do professor para os cursos de mestrado e doutorado que, como dito anteriormente, tem o objetivo de formar pesquisadores, indicam a valorização da pesquisa em relação às atividades de ensino. 


\section{O ENSINO E A PESQUISA: DOIS PAPÉIS DO DOCENTE UNIVERSITÁRIO}

Além dos problemas gerados pela falta da formação pedagógica, o docente do ensino superior também convive com a supervalorização da pesquisa em relação ao ensino, como aponta Garcia (2013). Assim, o prestígio profissional e o reconhecimento social do docente estão diretamente vinculados às suas atividades de pesquisa e à sua produção científica. $\mathrm{O}$ privilégio da pesquisa em detrimento ao ensino e à extensão (e o consequente distanciamento e desequilíbrio entre os três pilares da Universidade) é criticado por Cunha (2000, p. 45), ao afirmar que o docente " [...] constrói uma competência técnico-científica em algum aspecto de seu campo de conhecimento, mas caminha com prejuízo rumo a uma visão mais ampla, abrangente e integrada de sociedade".

Em tempo, é necessária uma análise política sobre a formação do docente universitário. A indissociabilidade entre pesquisa e ensino foi um dos princípios estabelecidos pela reforma universitária de 1968 que, em certo sentido, transformou o docente em pesquisador. Colocar o professor "dentro do laboratório" foi uma alternativa aderente ao contexto político da época, com o objetivo de distanciar o professor de questões sociopolíticas. Cunha (2000) afirma que esse distanciamento também foi consequência de um discurso pedagógico, nascido no mesmo contexto autoritário, que pregava a neutralidade da ciência e utilizava essa visão em contraponto ao pensamento crítico e à liberdade de expressão, que são pilares da universidade enquanto instituição histórica. Esta questão política reverbera até hoje na formação do docente universitário, que possui uma formação inicial demasiadamente técnica atinente a sua área disciplinar específica.

O instrumento de avaliação de cursos de graduação do Ministério da Educação (MEC) (INEP, 2017), que apresentamos anteriormente, aponta como um dos indicadores de qualidade do curso o número de publicações do corpo docente, avaliado quantitativamente no seu item 16. Nesse quesito, para obter nota máxima, o curso deverá possuir pelo menos 50\% do seu corpo docente com o mínimo de nove publicações nos últimos três anos. De forma análoga, na avaliação dos cursos de pós-graduação stricto sensu pela CAPES, a produção científica dos docentes é indicador de qualidade, sendo necessária, de acordo com o artigo $4^{\circ}$ da portaria 161 de agosto de 2017, a indicação, para cada docente permanente, de cinco produções nos últimos cinco anos (MEC, 2017). O mesmo não acontece com os aspectos didáticos da formação do docente em nenhum dos documentos. Observamos que a produtividade do professor na sua função como docente também não é considerada nas avaliações de larga escala conduzidas pelo Ministério da Educação, tais como o Exame Nacional do Ensino Médio (ENEM) e o Exame Nacional de Desempenho de Estudantes (ENADE). 
Portanto, embora não exista uma relação direta entre produtividade científica e eficácia docente, a produção de conhecimento - traduzida nas publicações em revistas indexadas e estratificadas - é a dimensão mais utilizada para a avaliação da qualidade docente. A análise dos documentos parece confirmar nossa percepção a respeito do privilégio das atividades de pesquisa sobre as atividades de ensino e nos aponta prováveis razões da falta de motivação para a formação pedagógica do docente universitário. A distinção profissional atribuída à pesquisa em detrimento da docência também reforça a ideia de que a atividade docente é inferior, diminui a autoestima e desmotiva o professor - o que repercute na sua identidade como docente universitário.

\section{FORMAÇÃO E IDENTIDADE DO DOCENTE DO ENSINO SUPERIOR}

Outra questão relacionada à formação docente no ensino superior é a sua profissionalização. De acordo com Masetto (2003, p. 30), a docência na universidade "exige não apenas domínio de conhecimentos a serem transmitidos por um professor, como também um profissionalismo exigido para o exercício de qualquer profissão". Assim, os professores são considerados como tal em função de um conjunto de competências que precisam dispor para exercer sua profissão.

Para uma melhor análise sobre a profissionalização do trabalho docente apresentamos alguns conceitos explorados por Pimenta (1996), Marcelo (2009) e Veiga (2009) sobre identidade profissional, um fenômeno inerente ao processo de profissionalização dos docentes. Identificar-se com a profissão é condição sine qua non para o exercício competente da profissão. A identidade profissional docente reflete o que o sujeito é em determinado momento (ou o que ele deseja "vir a ser"), como ele se percebe e como é percebido. Tal identidade extrapola a ocupação ou as tarefas que o indivíduo realiza. Ela se forja na necessidade de pertencimento a um grupo que compartilha uma ética e possui interesses comuns, atribuindo um sentido ao trabalho docente, se espelhando na imagem social do que significa "ser docente" e viabilizando a construção, desconstrução e reconstrução dessa imagem. No entanto, como alerta Zabalza (2004), os professores universitários se percebem, na área acadêmica, como pesquisadores e, no mundo do trabalho, como profissionais técnicos. Na verdade, são técnicos ou pesquisadores que, por motivos diversos, ministram aulas no ensino superior, o que mostra a atividade docente como secundária, além de não a caracterizar efetivamente como uma profissão.

Assim, observamos que a identidade profissional e a formação do docente universitário são questões inter-relacionadas (COSTA, 2007). Para que a identidade profissional seja construída, é preciso uma formação tanto inicial quanto continuada do docente para que ele se perceba como tal. De maneira análoga, é a formação docente que vai promover a

\begin{tabular}{l|c|c|c|c|c|c} 
() Rev. Educ. Perspec. & Viçosa, $M G$ & v.9 & n.2 & p.230-240 & maio/ago. 2018 & eISSN 2178-8359 \\
\hline
\end{tabular}


construção da identidade do docente, incluindo o conhecimento técnico-científico, a formação didático-pedagógica e a dimensão sociopolítica.

A lacuna existente na formação do "ser docente" tem como uma das consequências a supervalorização da experiência profissional da área disciplinar específica do docente do ensino superior, conforme apontam Zabalza (2004) e Veiga (2009). De fato, retomando o instrumento de avaliação de cursos do MEC/INEP analisado anteriormente (INEP, 2017), verificamos que cinco dos dezesseis itens avaliados sobre o corpo docente do curso estão relacionadas à experiência profissional de mercado e de magistério. Não pretendemos aqui negar a importância da experiência profissional específica do corpo docente para o desenvolvimento de um curso de qualidade. No entanto, retomamos Tardif (2002) que, ao elencar os diversos aspectos que influenciam na construção dos saberes profissionais, aponta a formação inicial e continuada, a experiência profissional, o conhecimento técnico-científico do conteúdo das disciplinas e a interação com seus pares no ambiente acadêmico, entre outras. Portanto, a experiência profissional é um dos vetores estruturantes da constituição do professor e da sua identidade profissional, o que não anula a necessidade da presença de outros vetores para alcançar a "força resultante", fazendo uma analogia com os ensinamentos da física clássica.

Outra consequência da falta da formação didática apropriada é o empirismo que caracteriza a ação do docente do ensino superior. Pimenta e Anastasiou (2010) e Tardif (2002) apontam que o professor do ensino superior leva consigo uma bagagem com as suas experiências prévias sobre o ensino, muitas delas vividas enquanto aluno, acrescidas das experiências vividas por seus pares, que também tiveram o mesmo tipo de "formação". Tais influências certamente direcionarão suas escolhas e, de uma maneira geral, o exercício de sua profissão. Assim, sem uma formação apropriada, o docente lança mão dessa bagagem, desenvolvendo suas habilidades apenas sobre suas impressões, sobre os casos de sucesso e insucesso de seus mestres e de seus pares, e sobre uma base empírica de um contexto de ensino de, no mínimo, vinte anos atrás. A formação empírica, além de não atender as demandas atuais, reforça a supremacia do técnico-científico sobre o pedagógico, enfraquece a atuação docente e desmotiva tanto professores como alunos (MORAES; TORRE, 2004; VEIGA, 2009; PIMENTA; ANASTASIOU, 2010). Além disso, como a formação está baseada na carga histórica e pessoal, cada docente tem o seu processo formativo, que é único (CUNHA et al. 2006). Em uma primeira análise, esse é um aspecto positivo e até mesmo desejável. Mas um olhar mais profundo pode mostrar uma consequência desfavorável, que é a diversidade de interpretações sobre o que seja educar, gerando ações em direções distintas. 


\section{CONSIDERAÇÕES FINAIS}

Com este artigo intentamos trazer à baila aspectos subjacentes à formação do professor da educação superior, a partir da revisão da literatura sobre o tema, tomando autores reconhecidos na área e da análise do Instrumento de Avaliação de Cursos de Graduação Presencial e a Distância do Instituto Nacional de Estudos e Pesquisas Educacionais Anísio Teixeira.

Esperamos com esta análise ter proporcionado ao leitor um melhor entendimento das questões atinentes à formação do professor universitário e dos problemas dela decorrentes: problemas referentes à identidade profissional e à sua formação pedagógica.

Constatamos uma precariedade nesta formação, o que reverbera diretamente na prática de ensino destes profissionais no ambiente acadêmico, levados a prestigiar muito mais a pesquisa em detrimento da ação docente propriamente dita, deixando-se resvalar para segundo plano aquilo que é ação precípua do docente universitário - ensinar.

Mas quais podem ser as alternativas para viabilizar uma mudança neste cenário? Acreditamos que, da mesma forma como o Ministério da Educação vem realizando campanhas pela titulação e regime de trabalho do professor para sensibilizar as IES da importância destes quesitos para uma educação superior de qualidade, é necessário incluir no instrumento de avaliação três novos critérios: i) Reconhecimento da formação stricto sensu na área de educação ou participação em programa de pós-graduação lato sensu de didática do ensino superior, quando o mestrado ou doutorado do docente e/ou do coordenador do curso for de área técnica; ii) Reconhecimento do empenho da IES na formação continuada do seu corpo docente, através de programas regulares de aperfeiçoamento docente, bem como incentivo regular à participação do corpo docente em escritos relacionados à metodologia do ensino superior; e iii) Reconhecimento da importância da presença da assessoria pedagógica nas Instituições de Ensino Superior como suporte ao corpo docente e como parte das políticas de desenvolvimento institucional.

O problema da formação pedagógica do professor universitário ultrapassa, pois, a nosso ver, a ação individual dos profissionais. Necessita de uma ação institucional, dentro da universidade, que possibilite a formação continuada dos seus docentes através de programas variados criados no âmbito dos institutos, como também necessita do envolvimento dos órgãos reguladores da educação superior no País. 


\section{REFERÊNCIAS}

DOI 10.22294/eduper/ppge/ufv.v9i2.942

BRASIL. Lei n 9394/96, de 20 de dezembro de 1996. Estabelece as diretrizes e bases para a educação nacional. Diário Oficial da União. Brasília, 23 dez. 1996. Disponível em: <http://legislacao.planalto.gov.br/legislacao>. Acesso em: 13 jul. 2006.

COSTA, Nilce Maria da Silva Campos. Docência no ensino médico: por que é tão difícil mudar? Revista Brasileira de Educação Médica, Rio de Janeiro, v. 31 n. 1, p. 21-30, jan./abr. 2007.

CUNHA, Maria Isabel. O professor universitário na transição de paradigmas. Araraquara: JM Editora, 1998.

CUNHA, Maria Isabel. Ensino como mediação do professor universitário. In: MOROSINI, Marília Costa (Org.). Professor do ensino superior: identidade, docência e formação.

Brasília: INEP/MEC, 2000. P. 45-51.

D’ÁVILA, Cristina Maria. Formação Docente na Contemporaneidade: Limite e Desafios. Revista da FAEEBA: Educação e Contemporaneidade, Salvador, v. 17, n. 30, jul./dez. 2008.

FERNANDES, Cleoni Maria Barbosa. Formação do Professor Universitário: tarefa de quem? In: MASETTO, Marcos (Org.) Docência Universitária. Campinas: Papirus, 1998. P. 95-112.

GARCIA, Carlos Marcelo. Formação de professores: para uma mudança educativa. Porto: Porto Editora, 2013.

INEP. Instituto Nacional de Estudos e Pesquisas Educacionais Anísio Teixeira. Censo da Educação Superior 2016: Principais resultados. Disponível em:

<http://download.inep.gov.br/educacao_superior/censo_superior/documentos/2016/censo_su perior_tabelas.pdf>. Acesso em: 20 abr. 2018.

INEP. Instituto Nacional de Estudos e Pesquisas Educacionais Anísio Teixeira. Instrumento de Avaliação de Cursos de Graduação presencial e a distância. Brasília, Distrito Federal, out. 2017. Disponível em:

<http://download.inep.gov.br/educacao_superior/avaliacao_cursos_graduacao/instrumentos/2 017/curso_reconhecimento.pdf >. Acesso em: 22 jan. 2018

MARCELO, Carlos. A identidade docente: constantes e desafios. Revista Brasileira de Pesquisa sobre Formação Docente. Universidade de Sevilha - Espanha, v. 1, n. 1, p. 109131, ago./dez. 2009.

MASETTO, Marcos. Docência na Universidade. 5. ed. Campinas: Papirus, 2003.

MEC. Ministério da Educação. Avaliação de Propostas de Cursos Novos (APCN) de pósgraduação stricto sensu. Portaria $\mathrm{n}^{\circ} 161$, de 22 de agosto de 2017. Disponível em:

\begin{tabular}{l|l|l|l|l|l|l} 
(C) Rev. Educ. Perspec. & Viçosa, $M G$ & v.9 & n.2 & p.230-240 & maio/ago. 2018 & eISSN 2178-8359 \\
\hline
\end{tabular}


<https://capes.gov.br/images/stories/download/legislacao/30082017-Portaria-N-161-de-22de-agosto-de-2017.pdf> Acesso em: 22 jan. 2018

MORAES, Maria Cândida; TORRE, Saturnino. Sentirpensar: fundamentos e estratégias para reencantar a educação. Petrópolis: Vozes, 2004.

MOROSINI, Marília Costa (Org.). Professor do ensino superior: identidade, docência e formação. Brasília: INEP/MEC, 2000.

PIMENTA, Selma Garrido. Formação de Professores: saberes da docência e identidade do professor. Revista da Faculdade de Educação, São Paulo, v. 22, n. 2, p. 72-89, jul./dez. 1996.

PIMENTA, Selma Garrido; ANASTASIOU, Léa das Graças Camargos. Docência no ensino superior. 3. ed. São Paulo: Cortez, 2010.

PIMENTA, Selma Garrido. Professor reflexivo: construindo uma crítica. In: PIMENTA, Selma Garrido; GHEDIN, Evandro (Org.). Professor reflexivo no Brasil: gênese e crítica de um conceito. 7 ed. São Paulo: Cortez, 2012. P. 20-62.

SOARES, Sandra Regina; CUNHA, Maria Isabel. Programas de pós-graduação em Educação: lugar de formação da docência universitária? Revista Brasileira de Pósgraduação - RBPG, Brasília, v. 7, n. 14, p. 577-604, dez. 2010.

TARDIF, Maurice. Saberes Docentes e Formação Profissional. Petrópolis: Vozes, 2002.

VEIGA, Ilma Passos Alencastro. Docência como atividade profissional. In: VEIGA, Ilma Passos Alencastro; D'ÁVILA, Cristina Maria (Org.). Profissão docente: novos sentidos, novas perspectivas. Campinas: Papirus, 2009. P. 13-21.

ZABALZA, Miguel Angel. O ensino universitário: seu cenário e seus protagonistas. Porto Alegre: Artmed, 2004.

\section{Sobre as autoras}

${ }^{1}$ Monica de Souza Massa - Universidade do Estado da Bahia - E-mail: monicamassa@gmail.com - ORCID: http://orcid.org/0000-0001-8212-5007

${ }^{2}$ Cristina Maria D'Avila Teixeira - Universidade do Estado da Bahia - E-mail: cmdt@ufba.br - ORCID: http://orcid.org/0000-0001-5946-9178 